\title{
Commentary: A Case of the Double Rarities
}

\author{
michelle mulder ${ }^{1}$ and Olivia D'Angelo ${ }^{1}$ \\ ${ }^{1}$ University of Miami Miller School of Medicine
}

May 29, 2021

\begin{abstract}
The authors report an exceptionally rare patient with findings of a bicuspid aortic valve in conjunction with a mature cystic teratoma in a middle-aged male presenting for symptomatic chest pain. Surgical resection and valve replacement were performed, confirming the rare cardiac tumor. While certainly interesting, this case highlights the importance of maintaining a broad differential diagnosis and the appropriate work-up, treatment and considerations for such rare pathology.
\end{abstract}

\section{Commentary: A Case of the Double Rarities}

Michelle B. Mulder M.D., Olivia M. D’Angelo M.D

University of Miami Miller School of Medicine/ Jackson Health

Dewitt Daughtry Department of Surgery

In this month's issue, Tao et al. present an interesting and rare case of cardiac pathology in an adult found to have a bicuspid aortic valve (BAV) in conjunction with a mature cystic teratoma. ${ }^{1}$ Individually, each entity is exceedingly rare with the reported incidence of $1 \%$ for BAV and $0.02 \%$ for primary cardiac tumors. ${ }^{2,3}$ Thus, this report of a patient with both extraordinarily uncommon pathologies marks the first of its kind.

The bicuspid aortic valve has long been associated with various congenital or hereditary disorders. However, traditionally these have included coarctation, aortic aneurysms and Turner's syndrome; not primary cardiac tumors such as the intracardiac mature cystic teratoma found in this patient. ${ }^{4}$ Nevertheless, independent of the associated cardiac disorders, accurate and timely diagnosis of BAV is essential as the sequalae of chronically untreated BAV can be fatal. ${ }^{5}$

Valve disorders are also commonly associated with BAV, particularly aortic stenosis, and less commonly, aortic regurgitation. ${ }^{6}$ Interestingly, while isolated BAV and severe aortic regurgitation, as observed in this patient, is relatively uncommon, when coupled with additional cardiac pathology, the incidence of aortic regurgitation significantly increases. ${ }^{7}$

While pathologically, mature cystic teratomas are benign, the long-term ramifications of a missed intracardiac lesion are anything but benign and can include mechanical outflow obstruction, tumor embolization, and arrythmias secondary to invasion into the conduction system. ${ }^{8}$ Fortunately for this patient, the concomitant presence of a bicuspid aortic valve progressed to symptomatic aortic regurgitation, prompting the patient to seek medical evaluation. This led to a full cardiac workup including multimodal imaging of which incidentally discovered the intracardiac lesion. Surgical resection was performed at the time of valve replacement followed by an uncomplicated postoperative course.

One may question the clinical significance of the authors report given the relative infrequency of either condition in the general population. Undeniably however, in our modern medical era of ubiquitous and arguably at times, superfluous, cardiac imaging, such rarities may become commonplace. Therefore, as we 
become increasingly reliant on routine noninvasive diagnostic modalities, so too must the clinician be readily skilled at deciphering which incidental findings require intervention, which require further diagnostic workup, and which can be merely observed. As the authors describe however, there are select circumstances where advanced imaging is warranted to properly diagnose cardiac lesions. Nevertheless, surgical excision remains the standard of care for definitive diagnosis of cardiac lesions. If nothing more, this case report serves as an imperative reminder to clinicians to broaden our differential diagnoses as statistically speaking, anything is possible. References:

1. Tao Z, Li Y, Zhao Y, Liu D. Incidental Finding of an Adult Intracardiac Teratoma. J Card Surg . 2021;in press.

2. Braverman A. The Bicuspid Aortic Valve and Associated Aortic Disease. In: Otto C, Bonrow R, eds. Valvular Heart Disease . 4th ed. Philadelphia: Saunders/Elsevier; 2013:179.

3. Bakaeen FG, Reardon MJ, Coselli JS, et al. Surgical outcome in 85 patients with primary cardiac tumors. Am J Surg . 2003;186(6):641-647; discussion 647. doi:10.1016/j.amjsurg.2003.08.004

4. Wang L, Ming Wang L, Chen W, Chen X. Bicuspid Aortic Valve: A Review of its Genetics and Clinical Significance. J Heart Valve Dis . 2016;25(5):568-573.

5. Kim S, Soltoski P, Karamanoukian H, Salerno T. Diagnosis in Valve Disease. In: Bayruns C, Lamsback B, eds. Cardiac Surgery Secrets . 1st ed. Philadelphia; 2000:47.

6. Roberts WC, Morrow AG, McIntosh CL, Jones M, Epstein SE. Congenitally bicuspid aortic valve causing severe, pure aortic regurgitation without superimposed infective endocarditis. Analysis of 13 patients requiring aortic valve replacement. Am J Cardiol . 1981;47(2):206-209. doi:10.1016/0002-9149(81)90385-4

7. Fenoglio JJJ, McAllister HAJ, DeCastro CM, Davia JE, Cheitlin MD. Congenital bicuspid aortic valve after age 20. Am J Cardiol . 1977;39(2):164-169. doi:10.1016/s0002-9149(77)80186-0

8. Bethea B, Richter A. Primary Cardiac Tumors. In: Yuh D, Vricella L, Yang S, Doty J, eds. Johns Hopkins Textbook of Cardiothoracic Surgery . 2nd ed. China: McGraw-Hill Education. 